I conclude from this fine collection that if the wrong of discrimination is, as I now believe, a matter of its quite contingent consequences, then there is really nothing distinctive about wrongful discrimination. Because we tend to think that there is, and if that thought persists despite the failure of the alternative theories on offer, it will mean that we are more certain of the wrongfulness of (some) discrimination than we are of the reason it is wrongful. But read this anthology (and the Lippert-Rasmussen monograph) and draw your own conclusions.

\title{
LARry AleXander
}

University of San Diego

Kamm, Frances Myrna. Bioethical Prescriptions: To Create, End, Choose, and Improve Lives.

Oxford: Oxford University Press, 2013. Pp. 599. \$35.00 (cloth).

This book is a collection of revised versions of some of Frances Kamm's previously published works in bioethics. It is divided into five main parts, each of which raises important bioethical questions: (1) death and dying, (2) early life, (3) enhancement, (4) allocation of scarce health care resources, and (5) methodology. Some chapters are organized around particular philosophical problems, others are responses to the works of other philosophers, and yet others provide conceptual groundwork for moral assessment of various bioethical issues.

The topics covered are quite diverse and not strongly intertwined. Unsurprisingly, a reader cannot easily extrapolate from what Kamm thinks about, say, ethical issues pertaining to Munchhausen Syndrome by proxy to her views on the permissibility of genetic enhancement. Still, definitely there are some topical connections between the chapters. Indeed, if there is one largely uninterrupted thread that runs through the entire book, it is Kamm's deontological moral view focusing on respect for persons. On this view, persons have a higher moral status than nonpersons. This comes out most clearly in her discussions of abortion and cloning. Another and related core conviction of hers is that this higher moral status is reflected in the facts that there are moral constraints on what can permissibly be done to us in the interest of bringing about better outcomes and that there are things we are permitted not to do even if doing them would bring about such outcomes.

In view of the length of Kamm's book alone, inevitably I must be highly selective in which bits I cover in this review. First, I say a bit about the content of the individual parts of the book. I then sketch three potential reservations. I conclude with some remarks about the qualities of the book overall.

The first part of the book addresses a mixed bag of issues, for example, conceptual issues in relation to death, axiological questions about what makes death bad, and normative questions about how we can permissibly bring it about. One important suggestion is that death is bad not just because of the goods that one would have enjoyed in its absence. It is also and independently thereof bad, because one ceases to exist - a bad, which presumably, is irrelevant to the wrongness of killing or letting individuals die who would suffer this bad whatever one does-and because, in cases of a wasted life, it means that one has no chance of 
rectifying one's past. Interestingly, Kamm also casts doubt on Velleman's redemptionbased account of why a "life on the incline" is better than one on the decline, all other things being equal, by imaging someone who, using a crystal ball, can foresee and in advance redeem future mistakes that he will make (19). Finally, she offers excellent critical discussions of physician-assisted suicide, defending the moral significance of the distinction between killing and letting die, and explores in depth the relation between euthanasia and respect for personhood and rational agency. Unlike many theorists writing on these matters, she downplays the role of intentions to permissibility.

Part 2 tackles various bioethical issues in relation to early life. Kamm offers an extended set of reflections on Judith Thomson's person who wakes up to discover that a frail violinist has been hooked up to her body such that the survival of the violinist now depends on her and the relevance of this case for the permissibility of abortion. While much of the discussion proceeds on the basis of the assumption, made for the sake of the argument, that fetuses are persons "from conception" (217), she also offers convincing arguments for why, despite their protestations to the opposite, few people really believe embryos are persons. For instance, most (correctly) believe that one can destroy one embryo to save more embryos and, yet, do not believe that one can destroy one person to save more persons. One practical upshot of this is that, in Kamm's view, research on embryos can be justified more easily than commonly assumed. Relatedly, she argues in a critical review of Dworkin's Life's Dominion that he misrepresents common sense as committed to the view that individual human life as such is sacred, for example, on the ground that common sense does not hold that it is never permissible to "kill the fetus in order to save the life of the woman who carries it" (169).

Part 3 addresses issues in relation to enhancement. Among other things, it contains a discussion of the duty of creators to treat those whom they create with equal concern and respect. Kamm thinks this duty is satisfied only when creators provide their createes with "the 'minima' appropriate to the life of a person" (267). This means that creating persons whose lives will inevitably be very short is impermissible: "even if we are unable to create anything better, there are strong reasons not to create a very short life, even if it will be worth living for the person being created" (268). Part 3 also rejects many, if not most, of the more common objections to cloning - in particular, cloned individuals do not have a lesser moral status than noncloned individuals have - and contains a thorough, critical discussion of the morality of human enhancement that takes its point of departure in Michael Sandel's rejection of most forms thereof. While not uncritical of enhancement, Kamm argues that enhancement and treatment are often confused and offers a perceptive analysis of the sense in which enhancement might reflect a desire for mastery and of the moral relevance of such a desire for the permissibility of enhancement.

Part 4 addresses the morality of the allocation of health care resources. Helpfully, it draws a distinction between goodness, on the one had, and fairness (which is essentially comparative) and justice - that everyone gets her due (where, presumably, what one is due is independent of what others get)- health carerelated concerns, on the other (363). The latter two concerns are best construed, Kamm thinks, as "side constraints' on the maximization of the good" and should not, or at least not only, be treated as "part of a state which it is our goal to achieve" 
(364). Also, in her view a fair and just distribution of health is "not inconsistent with inequality of (opportunity for) it" because "helping the worst off might, theoretically, require inequality of prospects for health" (372). Of course, unlike Kamm, some reject this view, contending that the situation she imagines is one in which to promote goodness, that is, better health outcomes (opportunities) for everyone and the worst off in particular, one regrettably has to treat the worst off unfairly. Kamm also provides an intriguing critique of the view that allocation of health care resources should aim to maximize quality adjusted life years (QALYs), for example, in relation to invidious as well as noninvidious discrimination against disabled (and nondisabled) people. One, but by no means the only, reason she rejects maximization of QALYs is captured by the Principle of Irrelevant Goods: "sometimes the fact that we can produce an additional good if we choose to perform one act rather than another is morally irrelevant" (425). Consider a situation in which we can save either nondisabled A from imminent death or slightly disabled B-B has a paralyzed finger-from imminent death. Suppose doing the former will produce slightly more QALYs. If we save A, A will enjoy not only many additional years but also the benefit of not having a paralyzed finger. In such a context, Kamm contends pace Peter Singer, the additional small benefit of not having a paralyzed finger is an irrelevant good, and procedures that take such benefits into account when allocating health care resources in life-and-death contexts might engage in wrongful discrimination against slightly disabled people.

The final part of the book is entitled "Methodology." Yet, most of the four chapters in this part discuss topics that do not fall under the heading "methodology" narrowly construed, that is, prescriptions about how to proceed to discover the truth about morality. Rather, they focus on issues such as self-knowledge about which beliefs about morality one holds and how philosophers should conduct themselves when members of committees that might actually influence policies. Committee membership might give rise to difficult choices in which, say, philosophers can bring about that their committee supports either a true conclusion conducive to the public good (e.g., terminating life-supporting treatment is permissible in certain cases) based on a false premise (e.g., that terminating life-supporting treatment is a case of allowing death, not a case of killing) or a false conclusion harmful to the public good but in a way that avoids commitment to the relevant false premise. Among the methodological issues in a narrow sense that Kamm addresses is the use of analogies. Pace Dworkin's claim that an analogy "is a way of stating a conclusion, not a way of reaching one" (55253), Kamm shows that this contrast is misleading. Analogies can be used as arguments in support of moral conclusions at the same time as their use calls for explanations of which factors render the putatively analogous cases analogous. Indeed, analogies can serve argumentative purposes in addition to the two purposes mentioned by Dworkin, for example, to identify explananda as when we have different intuitions about cases that appear alike in all morally relevant aspects.

While Bioethical Prescriptions is full of detailed insights in a way that is characteristic of Kamm's work, there were claims, and so on, that I found less persuasive. First, Kamm believes that while killing is morally worse than letting die per se, there are killings that are no worse than cases of letting die. These may 
have features of letting die that, unlike killings, cases of letting die have by definition and which render letting die per se less wrong than killing. Return to Thomson's violinist. Because the violinist has his life only because of being nourished by the supporter's body, and this person has no moral duty to offer aid in the first place, it is permissible for the innocent person to kill the violinist to avoid costs that would normally justify not saving from death. The violinist only loses what he has as a result of his wrongful attachment. As Kamm puts it, "the violinist's improved condition once attached cannot be the baseline relative which one must not harm him. The baseline is, rather, the condition he would have been in if he had never been attached to his supporter" (187).

This positive baseline view expressed in the previous sentence strikes me as unable to capture the moral significance of the killing-letting die distinction in the light of situations, where the attachment of the violinist preempted his attachment to a different supporter, who, let us suppose, would have been willing to tolerate this condition and who can now no longer initiate life support. Here the violinist loses something he would have had had he never been attached to the supporter (i.e., his life) were he to be detached. Yet, I suppose that many who share Thomson's and Kamm's intuition about the permissibility of detachment would not change their view about its permissibility in the light of the imagined fact about preemption. If so, Kamm's claim about which baseline relative to which one may not harm others is false. Adding a further twist to this case, we can imagine that a mere bystander had a right against the possible preemptor that she did not attach the violinist, but the preemptor would have done so impermissibly anyway. Here one would like to know more about Kamm's baseline. Is it moralized, as seems implied in parts of her discussion $(43,105)$, such that the violinist does not, in the relevant sense, lose anything he has independently of the supporter if the supporter detaches him? Or is it purely descriptive such (or moralized in such a way) that given that the preemptor would have aided impermissibly but not thereby wronged the supporter, the violinist is worse off in the relevant sense if the supporter disconnects him?

My second point concerns the notion of respect for persons. Kamm wants to ground many of her intuitions about (im)permissible actions in respect for persons. However, her book does not offer a unified account of this notion and, accordingly, it is hard to see what argumentative role it plays. In a way that is perfectly legitimate, she sometimes contends that certain actions are impermissible because they are incompatible with respect for persons, whereas sometimes she contends of other actions that they are not. Yet, it remains unclear what the general criterion for sorting cases into those involving compatibility and those involving incompatibility with respect for persons is. Generally, Kamm's approach is bottom-up - that is, she pays close attention to moral intuitions about particular cases. However, invoking the notion of respect for persons often seems to involve a top-down approach. Combining the two approaches is commendable. But in the absence of a fuller and explicit account of what respect for persons amounts to, it will do little to ground the moral concrete intuitions to which Kamm appeals.

Finally, consider Kamm's claim that in a life-and-death contest (where death for the individuals in question is a great harm), many lesser goods are irrelevant (453): "Suppose there is a volcano erupting on an island. We could either save 100 people on the left side of the island or 100 on the right, but not both... The 
people on both sides are paraplegics, but . . . if we save people on the right, we will unparalyze them; if we save people on the left, we will not unparalyze them" (453). Suppose we agree with Kamm that in this case we should toss a fair coin to decide whom to save. Does that show that being unparalyzed is an irrelevant good in a life-and-death contest? Here is a case which suggests not. Suppose that, unlike in Kamm's example, if we assist people on the left side there is a 11 percent chance that we will save their lives and a 1 percent chance that, if we save them, they will become unparalyzed, whereas if we assist people on the right side, there is a 10 percent chance that we will save their lives but a 99 percent chance that if we do so, they will become unparalyzed. In this case, it seems the fact that we stand a much better chance of unparalyzing people on the right side speaks in favor of using a lottery device that gives them a greater chance of being saved. If so, it is not true in general that the good of being unparalyzed is irrelevant in life-anddeath contexts.

Despite the ingenuity of Kamm's arguments it can safely be predicted that few will feel persuaded by them on all of the many questions addressed in this book. Still, it is extremely difficult not to be impressed with her powers of imagination and her moral perceptiveness. Many of the individual chapters brim with crucial insights, decisive counterexamples, and puzzling questions, and together they offer a top-notch deontological exploration into various matters of bioethics as well as into normative ethics in general. While little attempt has been made to give the collection the form of a coherent, well-shaped monograph - a number of arguments, examples, and principles appear in more or less the same form in different chapters of the book - it is still a very useful book. I strongly recommend it to students and scholars of bioethics as well as to philosophers interested in normative ethics in general.

KASPER LIPPERT-RASMUSSEN University of Aarhus

Katsafanas, Paul. Agency and the Foundations of Ethics: Nietzschean Constitutivism. Oxford: Oxford University Press, 2013. Pp. 267. \$75.00 (cloth).

This book defends a version of constitutivism inspired by the moral psychology of Nietzsche. A constitutivist theory is a metanormative theory that purports to establish the objective validity and the content of practical norms on the basis of the constitutive features of agency. At the outset of the book, Paul Katsafanas offers a most helpful general introduction to constitutivism as a kind of metanormative theory and its relation to traditional metaethical views. In chapter 2, he defends constitutivism against the most pressing objections. In chapters 3 and 4, he discusses and criticizes the two most prominent constitutivist accounts, those of David Velleman and Christine Korsgaard. In chapters 5-9, he develops his own version: Nietzschean constitutivism.

In this review I will focus exclusively on the constructive portion of the book. I won't discuss Katsafanas's criticisms of Velleman and Korsgaard and his interpretation of the historical Nietzsche (which he discusses at length in the appendix). 